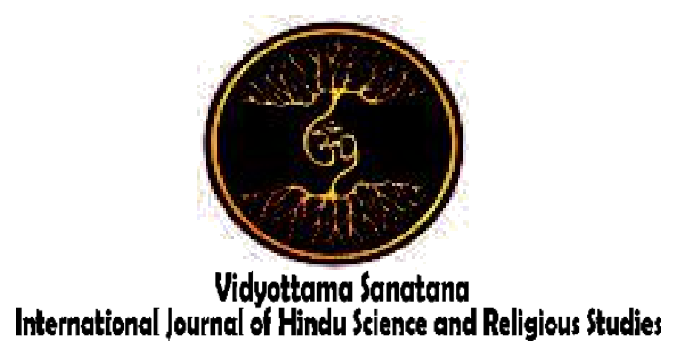

Vol. 3 No. 1 May 2019

\title{
MODERN SCIENCE VS. VEDIC SCIENCE
}

\author{
By: \\ Subhendu Das \\ Indian Association for the Cultivation of Science - Department of Physical Chemistry \\ United States of America \\ E-mail : subhendu.das@excite.com
}

\begin{tabular}{|l|l|l}
\hline Received: Desember 8, 2018 & Accepted: May 13, 2019 & Published: May 31, 2019
\end{tabular}

\begin{abstract}
Light can be understood only if we know the darkness. Similarly, the truths can be fully comprehended only if you know the falsehoods also. Many western philosophers, like Mark Twain, said "Majority is always in the wrong." To understand Vedic science one must therefore know: (a) The role played by the money power. The destiny of the entire earth is controlled by the money power. Without money none of us can survive. So, everything we do, do not do, and cannot do is motivated by our desire and security of money. (b) Yogic power, which is the highest level power, even above the money power, if you can acquire it. It controls the global destiny of the entire universe. (c) Modern science, which is the product of the global destiny, as well as the money power or the destiny of the earth.

Once you understand destiny, you will of course not blame anybody, including global, earth, or individual destiny. We will show with examples that all results of modern science are based on or derived from assumptions. Since assumptions cannot be valid for nature and engineering, modern science therefore cannot represent the nature, and be applicable to nature and engineering. For the same reason results of modern science can never be demonstrated. It must be realized that there is a heaven and hell difference between modern science and modern engineering. Since engineering uses science, all of engineering is full of patches and kludges, and therefore engineering is very unreliable, and pollutes environment. On the other hand the Vedic science is entirely based on observations, just like what Galileo observed. Vedic science does not therefore has any assumptions, and it is a record of what you see as happening in nature. The Vedic science also has another very crucial difference it observed two types of causes: (a) efficient cause and (b) material cause, behind every phenomenon. As a result Vedic science is valid for the entire universe and for all time, past, present, and future. We will illustrate all results of Vedic science with observations in nature. Such examples will be beyond comprehension of modern science.
\end{abstract}


Keywords: Newton's laws, QM, SR, Assumptions, Evolution, Placebo effect, Cause and effect, Root causes, Destiny law, Yogic powers, Vedas, Bible.

\section{Introduction}

There is a fundamental difference between modern science and Vedic science. Generally speaking, the modern science can be represented by a diagram

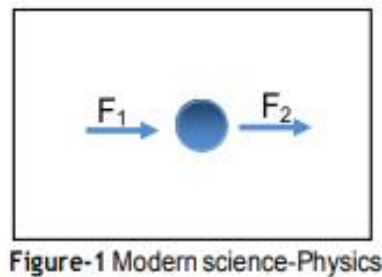

or the cause and effect law. The Vedic science represents the same phenomenon by Figure-2, where the F1 is replaced by another object, maybe a human being. Physics or modern science does not consider any active and conscious object behind any event, although engineering always does. Figure-2 is taken from the website [Billiard].

In one sense, it is true that the nature has only physical objects, which we sense using our sense organs, like eyes, ears, nose, etc. Such physical objects occupy space, they are continuously moving in space, and changing in characteristics with time. They take birth, grow to a maturity, then decay to its death, and vanish.

There are two key words in the English language: noun and adjective. A noun is a physical object, it occupies space, and we can see them. An adjective is a property, a quality, or a characteristic of a physical object. Adjectives therefore cannot exist on its own, it must require a noun. Thus the force F1 in Figure-1 cannot exist without an object behind it, like in Figure-2. This fundamental difference between the two figures creates a vast separation between the two sciences.

The rest of this article has the following contents. It has two major sections - Modern science and Vedic science. Modern science has several sub-topics - physics, like in Figure-1. In this figure a force $\mathrm{F} 1$ is acting on an object and producing another force F2. This diagram may represent the action reaction law of Newton

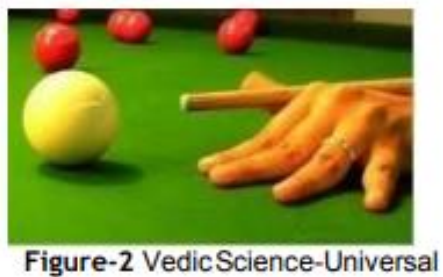

mathematics, economics, and medicine. And the Vedic science section mainly deals with destiny, cause and effect, and yogic powers. We begin with the definition of truth.

\section{Discussion \\ Definition Of Truth}

Modern society does not have a definition of truth. Merriam-Webster defines "a judgment, proposition, or idea that is true or accepted as true". The most common or popular understanding of the above is that you have your own truth and I have my own truth. Under that definition Galileo would still be wrong today. We give the following definition of truth (T1):

(T1):

(1) The laws of nature are the only truths,

(2) These laws are created by the objects of nature and their characteristics, and

(3) Nature always demonstrates all its laws.

Such truths are unique, universal, and eternal. Unique means one law will not contradict another law, they are independent, and there will be no redundancy. It also means everybody will understand them in the same way. Universal means if a law is valid in USA, it must be valid in China also. Similarly, if a law is valid on earth it will be valid in any other planet in any galaxy of the 
universe. And finally, eternal means, if a law was valid million years back, it will be valid now, and will remain valid million years from now. We will soon learn that this truth is neither objective nor subjective. Thus the truth is the only unifying force at all levels of the universe.

Objects of nature are humans, animals, plants, sun, moon, earth, galaxies, etc. Objects of nature are also TVs, air planes, missiles, electronics, computers, roads, bridges, houses, etc., because they are made from the objects of nature. Objects of nature can be sensed by our five sensors, like eyes, ears, etc. There are two very important things in our society which are all pervading and yet not objects of nature: money and real numbers. Of course, money is a real number too.

Characteristics are attached with objects of nature, they cannot exist independently, they are adjectives. Energy, for example, cannot exists without the sun. Thus the energy is an adjective and the sun is the corresponding noun. Similarly, vibrations cannot exists, it requires an object, like a string. The forces of nature cannot exits either, there must be a noun, and which is any physical object. Therefore, if you try to define nature using only by such characteristics, like in Figure-1, then that description will not represent the truth.

The nature is always demonstrating its laws, but we fail to recognize them, because we are living within these laws from our birth and we are part of the nature. The fact that the earth is moving, for example, we do not even realize that. Only when Galileo told us then we learnt that the earth is going round the sun. Even then his discovery did not change anything in our average life. Therefore, we will realize a law only when some extra ordinary events are demonstrated by nature or observed by any person. If you do the research, you will always find such events are described on the internet. Ayn Rand said - "Truth is not for all men, but only for those who seek it."
We will see that the laws of physics are not the laws of nature, but many fundamental laws of nature are described in Vedas. As an example gravity as described in physics is not a law of nature. There are many examples which show that a high level human yogi can levitate, float, and even walk or fly in air, above the ground [Michael]. Birth-maturity-death of every object is an universal truth. We will find that reincarnation, destiny, etc. are also universal truths. And nature always demonstrates them. If you read carefully then you will find the above definition of truth (T1) is embedded in Vedas, Bible, and many books of all religions.

\section{Destiny Law}

The most powerful law of nature is described in the Vedic science and it is known as the destiny law. It is the highest level law of nature. Everything in the entire universe is controlled by this law. All other events that happen, are all derived or influenced by this destiny law. In simple terms this law can be described as:

(1) All events in the universe, and in our life in particular, are predetermined, and planned already.

(2) All events that will happen, moment by moment, short terms, and long terms, can be precisely predicted with all details, and before the events happen, by any high level yogi with the power of third eye.

An immediate consequence of the destiny law is the absence of freewill. It is very easy to understand that we do not have freewill. All our actions have reasons, without any reasons we never do anything. But since reasons come before we act, it means that our present action is controlled by our past reasons. Thus no one can have any freewill at present moment. Therefore we are guided moment by moment by the destiny law.

We also do not have any choices or options. This is so because we analyze every option one by one, since our mind works 
only sequentially. When we take any one of the options and analyze it, our freewill does not work for that option and for that time slice, as explained before. Our things happen in the same way for next time slice and for the next option. Thus in every moment we have only one choice with no freewill.

The above explanation is based on the action-reaction law of Newton, we only injected the principle that there is always a time gap between the two events: action and reaction. This law is same as sow-reap statement of Bible and the cause and effect statement of Vedas. However, destiny law and its mechanism is lot more complex than the simple action-reaction law, as can be demonstrated by the following example.

Observation 1: A yogi from India came to visit a research institute in USA during the early seventies. Pat Norris came to his office to see him. As she entered his office, the yogi told her to ask some questions. One by one she asked seven questions. Then the yogi picked up a paper from his desk, turned it upside down, and gave that to her. In that paper all her seven questions were already written, along with their answers. Pat said one was wrong, and another one was partially correct, rest were all correct [Green]. Thus even for moment by moment, life can be precisely predictable, before the events happen.
There is no probability or randomness at any level. Everything is controlled by the global destiny. The above casual demonstration was not performed under video camera, so it will be difficult to find why the results were not $100 \%$ correct, which usually is the case for high level yogis. There are many such precise demonstrations in the literature and can be found on the internet.

The above Observation-1 says that (1) we are robots, we do not have any freewill. (2) Everything that we do is already written in the memory of the universe. Some call this memory as Akashic record. (3) Any high level yogi will be able to read this memory and predict our actions exactly. (4) Our soul also reads that same memory and performs the actions. This destiny mechanism can be described by the diagram in Figure-3. The photo of the thinking man in Figure- 3 is taken from [unsplash].

In Figure-3, the memory of $\mathrm{Mr} . \mathrm{X}$ is given as a sequence of entries. This sequence is finite since every object lives only for a finite length of time. Similarly, memory of other humans like $\mathrm{A}, \mathrm{B}, \ldots$, and $\mathrm{Z}$ are also stored in the universe. All such memories can be read by any advanced yogi at any time. This

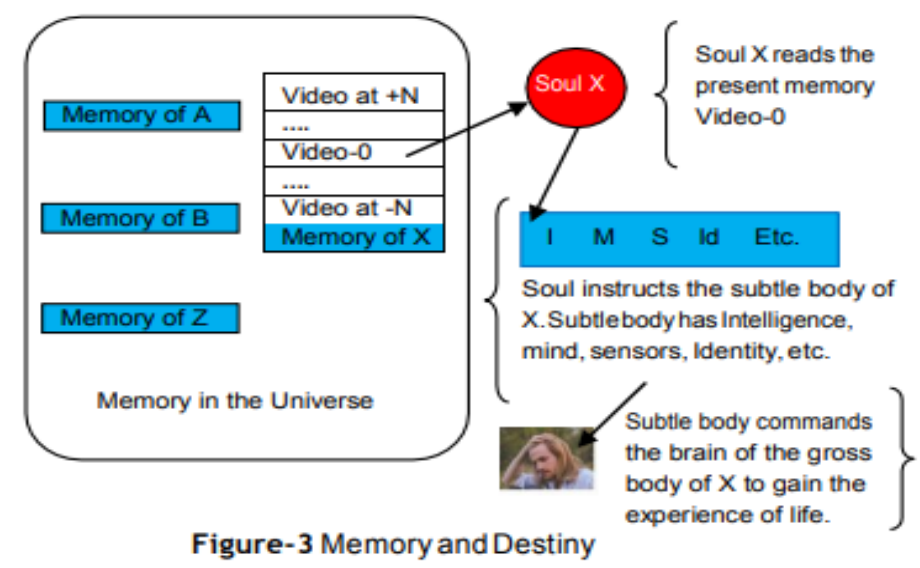

memory is permanently written in the universe, and is protected by the law of conservation. The soul of $\mathrm{Mr}$. X reads the memory and performs its action accordingly.
This data is used by the soul to control the brain, which in turn controls our active organs for performing physical actions. This Figure-3 shows: (1) How destiny works (2) 
Why it is predictable and (3) Why everything in the universe is like a robot. In the diagram there is a concept of subtle body, which contains Intelligence, Mind, Sense organs, Identity, etc.

Mathematical Model: Destiny law can be comprehensibly described using a simple mathematical model. The model will only illustrate the existence of an unique global destiny, and the destiny of every individual is linked to this global destiny. This model cannot be used to solve for destiny of any event at any space time point. However, it shows the existence and uniqueness of the destiny law.

All objects in the universe are continuously and simultaneously interacting with each other and for eternity. This law is quite obvious and is known as simultaneity law. We can describe this phenomenon by the law of conservation or the sigma law [Das, 2012-1]:

$$
a_{1} x_{1}+a_{2} x_{2}+a_{3} x_{3}+\cdots+a_{N} x_{N}=0
$$

In the above expression all $\mathrm{x}$ variables are actions of all objects in the universe. They can be trillions in number but is finite, since universe is finite. The coefficients of each variable are used as scale factors or parameters that magically transform every action into a real number. The addition is zero, because law of conservation says nothing can be created or destroyed, they can only be transformed in shape or size and can be transferred from one point to another point by motion. Since everything is continuously changing we can rewrite the equation (1.1) and then redefine the coefficients using the same name:

$$
\dot{x}_{1}=a_{1} x_{1}+a_{2} x_{2}+a_{3} x_{3}+\cdots+a_{N} x_{N}
$$

Clearly the above expression will be valid for all variables, then we can repeat the equation (1.2) for each variable in the left hand side giving us a set of simultaneous differential equations. This equation then can be written in the matrix form as:

$$
\dot{x}=A x, \quad x\left(t_{0}\right)=x_{0}
$$

It is well known that the above differential equation has an unique solution for any given initial condition. This shows that global destiny is unique and exists for all time. Thus no one has any freewill to change anything in the universe. If anything changes then everything changes. In the above equation there is no control force, because we have considered the entire universe, and there is no outside from which a control force can come. Everything is included in the original sigma law (1.1).

Corporate model: The concept of global destiny is clearly visible in the corporate model of our modern world. Before we start a project, we all come together, define the tasks that need to be performed, we assign tasks to correct individuals, we then define our schedule and interfaces with each other. This project plan is nothing but the global destiny of our corporation. Every day when we come to work we know exactly what we have to do. We cannot change our mind, and if we do then the entire project destiny for everybody will be disturbed. And why would we change our mind, when we jointly created the plan? We can then see how simultaneity law is working inside a corporation to produce an unique destiny.

When I am alone in the universe, I can have freewill. As soon as I get a life partner, my freedom reduces, we now have to accommodate each other to live together. When we get kids our freedom decreases again, when we start working for a corporation, our freedom again decreases. You can then imagine when all the souls of the universe are together and simultaneously interacting, every action becomes completely restricted and precisely defined. Destiny then essentially means that every activity has thousands of reasons as shown by the model (1.3). No single person is responsible for any single event. All events are created by all persons. Every event is a result of continuous action reaction for all past present and future times. Nothing can happen without taking care of all future 
events. Thus model (1.3) justifies the description of Figure-3.

The activities of UFO-ETs with humans on earth is truly a representation of simultaneous interactions at the global stage of the universe. This interaction is not just physical it is also technological.

\section{Modern Science}

Since everything is controlled by the destiny law, the state of the art of the modern science and therefore our present society is also controlled by the destiny law. Thus we cannot blame anybody about the status, that is, we are all equally responsible for such conditions. This was all planned long before the modern society was conceived. We will examine the characteristics of the modern science in the following areas (1) Physics, (2) Mathematics, (3) Economics, and (4) Biology. We will find that there is an unified theory behind all activities of the modern society and they are completely controlled by money and money power. This money, of course, is also a product of the destiny law, and has naturally evolved over thousands of years.

\section{Modern Science - Physics}

Sending Galileo to jail, in 1633, was the turning point in the evolution of our modern society. Scientific community realized the consequences of going against money, money power, and discovering the truth. Carroll Quigley (1910-1977), a professor at Georgetown university and a mentor of the US President Bill Clinton (1993-2001), mentioned in his book, Tragedy \& Hope [Quigley], that there are three negatives in our education system, and one of them is "never to teach the truth". After Galileo, therefore, the scientific community stopped observing the nature and decided to start with assumptions instead, to create false theories. This way people can be kept busy and yet in ignorance. Satyajit Ray (19211992), an Oscar winning film director, in one of his films, In the land of diamond king [Ray], said - "shutdown the schools, burn all the books, jail all the teachers. More you teach them, more they learn, and more they disobey".

To illustrate the point, and be more specific, let us select Newton's First Law, which we have studied in our high school science classes. Newton (1643-1727) said [Serway] - "(1) In the absence of any unbalanced force (2) an object will continue in motion (3) in a straight line (4) with a constant velocity."

Have you ever observed any such object on earth or in space? No, of course you have never seen such an object. Item (1) in the law, is the assumption of isolated environment, which is impossible, because gravitational forces are always there. In the deep space and also on earth, the sum total of all gravitational forces from all objects of the universe, at every point in space, is nonzero, and is continuously changing in both magnitude and direction, because all objects in the universe are continuously moving. Since all objects are continuously moving, the item (3) is also not feasible, there is no straight line in the universe. Thus Newton's first law is completely wrong, false, meaningless, and cannot work in nature.

This has happened because Newton did not observe the nature, like Galileo did, and instead started with two assumptions (1) and (3). The following statements can be found in a physics textbook [Ferraro, p. 8] about Newton's first law:

"We could hardly sustain that this principle (First law) is a strict experimental result. On the one hand it is not evident how to recognize whether a body is free of forces or not. Even if a unique body in the universe were thought, it is undoubted that its movement could not be rectilinear and uniform in every reference system."

If you read carefully you will find that all theories of mathematics and physics started with assumptions, and therefore none of them can be correct. Nature, and engineering which is part of nature, cannot 
accept assumptions. Therefore none of these theories can be verified by any engineering experiment. Engineering will always automatically eliminate all assumptions making the theories to fail.

Interestingly, Einstein assumed existence of inertial reference frame, which is a frame that moves with a constant velocity in a straight line. That is, Einstein assumed Newton was correct. Einstein also made another major assumption - that the light speed is constant, which has not been proven correct yet [Das, 2014-1]. Heisenberg's uncertainty principle similarly assumes that the position and the momentum of a particle are related by Fourier Transform (FT), a completely unrealistic assumption, and he also ignored the fact that the FT uses infinity, which is not there in nature [Das, 2013-1]. A physics textbook confirms the above assumed relation:

"Further, since the wave function $\Psi(\mathrm{x}, \mathrm{t})$ is a probability amplitude for position, its Fourier transform

$\Psi(\mathrm{p}, \mathrm{t})$ is the probability amplitude for momentum" [Phillips, p. 44].

Assumptions vs. Approximations: There is a difference between assumptions and approximations. If you have ten forces acting on an object, and if you consider only one of them, then it is an approximation. But if you neglect all of them, that is, consider an isolated environment, then that will be an assumption. Besides there are other kinds of assumptions too. For example using infinity is an assumption. A large number is never an approximation for infinity. Replacing infinity by any finite number, will change the mathematical theory completely [Das, 20111]. Taking light speed as constant is also an assumption. Existence of a straight line in nature is another similar kind of assumption. God, as the creator of the entire universe is an assumption also. An important thing to remember is that nature and engineering cannot accept assumptions and will remove them automatically from all engineering experiments. Thus no experiment can verify any theory. We must observe the nature, and that is the only way to find the truths.

Since all assumptions are invalid for nature, then they are all false. Something that is false can never become true, no matter what you do with it. Thus all theories will remain false, because they are nothing but only manipulations of the initial assumptions. Thus entire mathematics and physics must be wrong or false for nature. Then why are we doing it - because we are not free, and are guided by the destiny. Destiny basically means trillions of reasons, spanned over billions of years, past, present, and future.

It must be understood clearly that there is a heaven and hell difference between science and engineering. Engineering is correct, because engineering uses objects of nature. However, since engineering also uses false theories and false money, engineering is full of patches and kludges, therefore very unreliable, and pollutes environment. We give an example to illustrate the difference between the science and the engineering.

GPS system: We are all very familiar with the GPS technology, because most of our cell phones use GPS receivers, which receives data from the satellites rotating around the earth. In physics there is law called Kepler's law, which says that a satellite will rotate around earth in an elliptical path, and then the law gives a mathematical formula to find the position of the satellite at any point in time. This formula did not work for GPS satellites. So, engineers, physicists, and mathematicians modified the law significantly but still could not make the Kepler's law work. Eventually the GPS ground system was used to directly measure and find the position of the satellite, upload that data to GPS transmitters, which then broadcasted that data to our hand held receivers to provide the desired accuracy. Even this did not work properly, so the ground station repeats the process every two hours or so, to satisfy the accuracy requirements. 
Why did Kepler's law fail to work? The assumption ellipse is defined only on a plane of paper and around a stationary center point. But earth is moving around sun, and takes the satellite with it. Thus the path of the satellite can never be an ellipse. There are other objects, like moon, and planets of the solar system, which also influence the position of the satellite. The sun is not stationary either, it is travelling along one of the spirals of our galaxy, that spiral is also rotating around the central core of the galaxy. Thus the path of the GPS satellite is immensely complex and beyond our imagination, and therefore cannot be translated using a simple symbolic language like mathematics. This example shows why our engineering is so full of patches and kludges. Consequently, our engineering cannot be reliable at all.

The above GPS example shows that mathematics is not good for nature and engineering. In reality mathematics is not necessary at all for designing engineering systems. All we need is good measurement systems involving good sensors just like humans have. Using measurements, just like GPS ground system, we can design any engineering system in much more reliable way [Das, 2012-2].

\section{Modern Science - Mathematics}

If you write (M1): $1+2=3$, most people will understand its meaning. One orange plus two apples make three fruits. But to a mathematician this is a completely wrong application of mathematics. One, two, and three are real numbers, they are not for apples, oranges, etc. One, two, and three are points on a real line, which is a straight line. And the numbers are equal distance apart starting from the point zero. Thus addition is defined only for real numbers, and not for anything else. Here only distances are added, two apples cannot be added. There are many such properties for real numbers. Any textbook on real analysis will describe them [Trench]. Thus real numbers are not objects of nature and therefore, must be false, and cannot be applied for the description of nature.

There is no straight line in nature. Since all objects in the universe are moving continuously, no three points on a straight line can remain on that straight line for more than a moment. Thus the foundation of mathematics, a straight line, is not meaningful in nature. Since engineering uses objects of nature, and also interacts with nature, mathematics cannot be applied to describe both engineering and nature.

Infinity is a very important concept in mathematics, however, infinity is not there in both engineering and in nature. The characteristics of any mathematical theory that uses infinity will magically change completely if you replace infinity by any finite number, however small or large. We can illustrate it [Das, 2011-1] using the Laplace Transform (LT), a very commonly used tool in engineering and physics. Similar effects can be shown [Das, 2013-1] for the Fourier Transform (FT) also.

Infinite Laplace Transform (ILT): Laplace Transform (LT) is defined using an integral as shown in (1.1):

$$
F(s)=\int_{0}^{\infty} e^{-s t} f(t) d t
$$

In expression (2.1) the variable $t$ is usually considered as time. The integral limits show that the time must be valid from zero to infinity. Thus the function $\mathrm{F}(\mathrm{s})$ on the left hand side, called infinite Laplace transform (ILT), will be valid only for infinite time systems. Consider the step function defined over infinite time:

$$
f(t)=1 \text { for all } t \geq 0
$$

Using the definition (2.1) we get the expression for the infinite Laplace transform (ILT):

$$
\begin{aligned}
\mathcal{L}(1) \quad & =\int_{0}^{\infty} e^{-s t} \cdot 1 \cdot d t \\
& =\frac{1}{s}-\frac{1}{s} e^{-s T} \\
& =\frac{1}{s}
\end{aligned}
$$


The last step is obtained by using infinity for $\mathrm{T}$ in the previous step. We can see from (2.4) that the ILT has a pole at $\mathrm{s}=$ 0 . This creates singularity in the engineering systems. Employees in corporations use such techniques, without knowing that they are using infinite time theory in finite time engineering, leading to complex patches and kludges. This is obvious because we are using wrong theories.

Finite Laplace Transform (FLT): Let us now consider an example with finite time $\mathrm{T}$ to bring out the fact that the Laplace transform is based on infinite time assumptions, that is, it cannot be used for finite duration signals. The finite duration step function $\mathrm{f}(\mathrm{t})$ is defined by

$$
f(t)= \begin{cases}1 & 0 \leq t \leq T \\ 0 & \text { otherwise }\end{cases}
$$

Using the definition (2.1) we get the expression for the finite Laplace transform (FLT):

$$
\begin{aligned}
\mathcal{L}_{T}(1) \quad & =\int_{0}^{T} e^{-s t} \cdot 1 . d t \\
& =\frac{1}{s}-\frac{1}{s} e^{-s T} \\
& =\frac{1-e^{-s T}}{s}
\end{aligned}
$$

Observe from expression (2.7) that the FLT does not have any poles, that is, a value of infinity for $\mathrm{F}(\mathrm{s})$ at the origin. At $\mathrm{s}=0$ the expression (2.7) takes 0/0 form. The FLT completely changes the nature of LT. In this case the FLT is an analytic function with no singularity. The situation will be true for all kinds of functions, and not just for step function. Thus real engineering, which is a finite time system, does not have any poles.

This example shows that just because something is used in engineering and engineering works, it does not mean that this something is correct.

An entire theory of control systems, signal processing, and communication engineering has been developed using this pole-zero concepts of Laplace Transform. Transfer functions, Bode plot, root locus, are taught extensively in undergraduate classes.
You can now see that they are all wrong. Finite time engineering cannot have poles.

The Laplace Transform theory must be revised and rewritten for applications in finite time engineering [Das, 2011-1]. For embedded engineering applications, ILT is not a correct tool and its use will make the embedded engineering software unreliable. But in practice that is what happens, engineers will have to add patches and kludges to make engineering work. Thus engineering has become complex because we are using wrong theories.

In reality all theories are wrong, and none of them works or can work for any engineering applications. In fact engineering can be designed completely without any theory. Human body is the best example of nature's engineering work. We do not use any theory when we walk, or when we do our daily activities. This happens because we have the best sensor technology inside our body. The same can be done for engineering also [Das, 2012-2].

It should be mentioned that, since mathematics is wrong, and physics uses mathematics then physics must be wrong too. By wrong or false, we mean that the subject is not applicable for engineering or nature.

Modeling an Apple: Can you describe an apple using mathematics? Did you ever realize that different parts of the same apple has different tastes? How did that happen? This means every molecule of the same apple has different tastes. This in turn means every atom, and therefore every electron has different tastes. But physics do not recognize such properties of electrons. There are billions of electrons in an apple, and we cannot model them using any mathematical algorithms. This complexity is there in every object of nature and therefore mathematics cannot be used to describe any object of nature. If you cannot describe one apple, then you cannot compare two apples. Thus it is wrong to say that this apple costs $\$ 10$ and that apple costs $\$ 15$. 
You cannot even compare the shapes, colors, etc., of any two apples. It is impossible to identify the position of a point on the surface of an apple, using any algorithm. Where would you place the origin of your coordinate system on one apple? Can you locate the same point in another apple? No, you cannot, two apples are completely different. If you think this way you will realize the immense complexity of nature, which is beyond the capabilities of our mathematics. Thus mathematics is false or wrong for both engineering and nature.

\section{Modern Science - Economics}

Money is a real number, therefore money must be false. Economy must be false then, since money is false. We can verify from the graphs of the economic performances that the wealth gap is increasing and poverty is also increasing in USA. We can also see from the graphs that our economy is never stable, it goes through recessions every now and then; and these are planned events too [Das, 2011-2]. In the figures 4 and 5 , the horizontal $\mathrm{x}$-axis represents years from 1967 to 2009. The vertical bars represent the economic recessions, their widths represent the duration of the recessions. The vertical yaxis has been normalized to unity value of income.

Thus the economy that creates poverty, repeated recessions, wars, discriminations, etc., cannot be good for the society, and therefore must be false. It should be obvious that it is the false money that caused such a state of the art. Something false can never

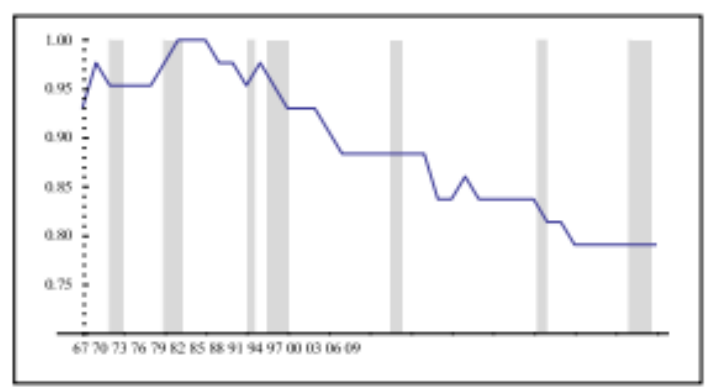

Figure- 4 Income of bottom fifth and Recessions create anything true. You do not need to understand economics, if you observe that a homeless man lying on the side walk in the USA, you will immediately know that there must be something wrong in the economy.

Profiting is stealing: Profiting is the core activity of our economic system, and can be considered as the foundation of our present Central Bank Economy (CBE). Let us illustrate how profiting creates poverty. A CEO manufactures a product at $\$ 5$ per unit. He then sells it at $\$ 15$ per unit, thus making a profit of $\$ 10$ per item. Thus the cost of the product is $\$ 5$ for the CEO, and it is $\$ 15$ for all of us. Thus every time we buy an item from this CEO we lose extra $\$ 10$. And the CEO becomes richer by the same amount.

This way every business is stealing wealth from people, and this stolen wealth gets accumulated to a small number of people making them richer and the poor is getting poorer. There is no win-win under the CBE, it is always win-lose. Win-lose is a law of nature, in physics it is called the law of conservation. In every apparent win-win case, if you look carefully, you will always find a third party who will be loser. Giving higher salary, interest charging, creating unemployment, creating recessions, etc., are all methods of creating poverty by transferring wealth from the poor to the rich. This is happening because money is a real number, and therefore false, and can be easily manipulated to violate all the laws of nature. This shows that the CBE is not a natural economy, it is artificial, yet it is controlling the entire humanity and our destiny.

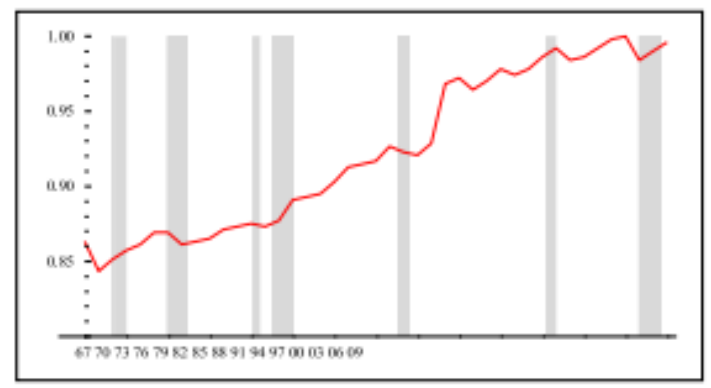

Figure-5 Income of top fifth and Recessions 
The two graphs in figures 4 and 5 show how top fifth of the population are becoming richer over the years and it will always continue to do so as long as money is there. In the same way you can see how the bottom fifth of the population is going downhill and becoming poorer. Thus the real definition of poverty is the wealth gap between the rich and the poor, because that wealth gap is the true measure of how much is stolen from the people. For details about the data sources and the processing of data, take a look at [Das, 2011-2].
Every object, including all humans, of this earth has been assigned a price tag. Therefore you cannot eat if you do not have money. You cannot also sleep on the sidewalk, because someone else owns that side walk. Thus by manipulating false money the CBE has taken the democracy away from the people. Since the money is false, all such assignments of money value to objects of nature, must be false also.

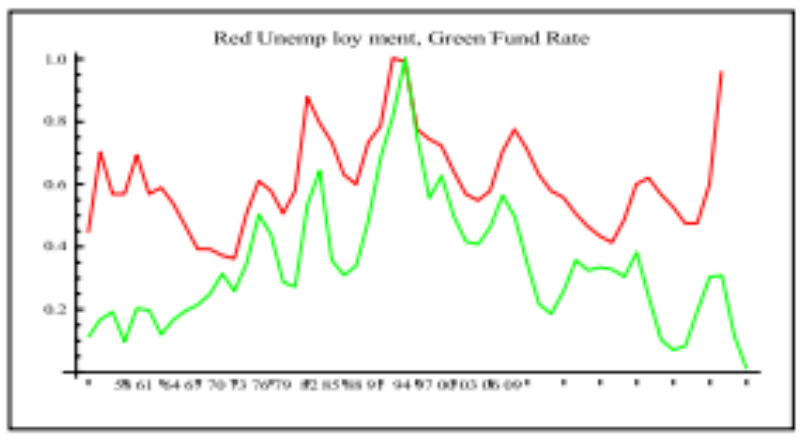

Figure-6 Funds rateand Unemployment

Thus there is no reason to justify that apples is $\$ 10$. Similarly, you cannot rationalize that, Mr. X will get

$\$ 10 / \mathrm{hr}$ and Mr. Y will get $\$ 1000 / \mathrm{hr}$ as their salary. Thus false money is forcing us to accept anything or do anything that CBE wants us to do. Anybody can be paid to kill anybody, and the person must accept that, otherwise he or his loved ones will be killed. For the same reason, physics also can be wrong, because that is what CBE wants. The entire education system must be wrong, because it is controlled by money power originating the central bank $(\mathrm{CB})$.

The graphs in Figure-6 show how the core interest rate, which is also known as Federal Funds Rate (FFR), can be manipulated to create unemployment. FFR is controlled by the central bank (CB), independent of anything, and the government does not have any control over CB. On the other hand the $\mathrm{CB}$ can completely control the government by controlling its supply of money, and its lobbyists by using the well known carrot and stick policy. The two curves in Figure-6 show almost complete match in shape. Again, for the exact details, of how the data was obtained, and how graphs were transformed, see the original source [Das, 2011-2]. It was Ben Barnanki, a professor at Princeton, and later the chairman of the Fed, who first pointed out such feature of FFR [Bernanki].

Moneyless economy (MLE): It may appear that there is no way to run an economy without money, but that is not correct. Since money is false, money cannot be necessary to run any real economy. Let us look at money in a different way: Why do we need money? You give me money so that I can work for you. Similarly, I need your money to buy my food and shelter. That is the only purpose of money. Why not then I work free for you and the governments give us free shelter and food. That is, we work free and get everything free. This system is called moneyless economy (MLE).

Under MLE there will be no poverty, no unemployment, and all of us will have full 
democracy. MLE will automatically eliminate wars, pollutions, migration, racism, gun violence, religious violence, etc. MLE can bring heaven on earth. MLE will also create One World Order, a dream objective for the CB. For more details on MLE take a look at [Das, 2012-3].

\section{Modern Science - Biology}

Placebo Medicine: Any time a new medicine is tested, the medical industry tests the drug to a selected group of humans. Then they divide the group in two sub-groups. One group is given a placebo medicine and the other group is given the real drug under test. Placebo medicine is a false or fake medicine, like plain water, or sugar pill, etc. The drug industry has the data to show that all diseases have been cured by placebo medicine. This then raises the question - is the drug effective or meaningful? Or in other words is medicine effect same as placebo effect? Modern medicine does not have any answer to such questions.

Similar results have been observed in the case of placebo surgery. People have been healed by fake surgery, where in reality nothing was done to the patient, but the patient was made to believe that a real surgery was performed on him. This again shows that modern health care system does not know how things work in practice or what actually the real cause behind such placebo or medicinal treatments.

There is a video that demonstrates, in real time under ultra sound, that a yogi cures cancerous tumor within three minutes [YouTube, 2014]. UFO-ETs have used the similar methods on human abductees to activate their yogic powers. There are hundreds of videos on human abductees, describing their experiences and their body implants. One UFO-ET and human hybrid woman has given eye-sight to a blind woman, and the case is documented in a book written by the mother of the blind woman. There are many such examples of miraculous cure, written in many books on yogis, performed by high level yogis. Again, about UFO-ETs you should not rely on governments, but rely on your own research on the internet documents.

Evolution Theory: This theory says that objects evolved from one form to another form. There are many different types of fossils that show such evolution. But these are only effects of evolution. Thus evolutionists did not provide any explanations about the causes of such effects. If the causes are not known then the effects are not understood also. They say that natural selection causes evolution [NAS]. But what is natural selection? Again it says environment selects the traits. But environment is same as nature. Thus the causes or the root cause has not been explained, justified, or observed in nature by the evolutionists.

Some articles say that the DNA changes, genetic code changes DNA, viruses change the genetic code. But the same question remains - what causes a virus to change things. If a virus can change something, then it means the virus has freewill. But that is not possible, we have shown that nothing, no living or nonliving object, has any freewill. It is the modern science that says there is no freewill, and that is correct.

As mentioned, if you ask question after question, then you will find that the last question has never been answered correctly. If the last answer is not known, then the first answer is also not meaningful. And contradictions for such answers can always be observed in nature, because nature always demonstrates the truth. We have to learn to observe the nature carefully, just like Galileo did. We need to change our scientific process to search for truth. However, yogic power with divine vision will always reveal the truth.

The Two Sciences: We can thus see that there are some fundamental differences between modern science and Vedic science. Most significant one is that the modern science is based on assumptions; and the Vedic science is based on observations of 
nature. Another difference is that in modern science there is no concept of root causes, as a result it often does not know which one is the cause and which one is the effect. The scientific process is also very wrong; it tries to do engineering experiments, but does not know that assumptions cannot be verified, because engineering or nature will automatically reject them. Thus if you cannot verify the assumptions then no theory can be verified also, because all theories of modern science are only manipulations of assumptions. It must be recognized though, that all engineering experiments are correct, and they do demonstrate some laws of nature, but they do not verify any theory of modern science.

\section{Cause And Effect}

We never do anything without any reasons. Our reason is the cause, and our action is the corresponding effect. Without a cause nothing can happen, not even evolution or creation. Modern engineering recognizes two types of causes [Virupakashnanda] - (a) material cause and (b) efficient cause.

Observation2: You make a pot out of clay. Pot is the effect and clay is the material cause. Without this clay that pot cannot be made. We must also have a specific kind of clay to make a specific kind of pot. Not any pot can be made from any kind of clay. In addition, you must require an expert human being, that is, a conscious, intelligent, and efficient person, who can correctly rotate the pottery wheel, and also simultaneously use his hands properly, to transform the clay into a pot. Not anybody can create such a pot, he must be efficient for that specific task. Without such a person the pot cannot be created. This human being provides that efficient cause.

All engineering corporations look for experts who can provide such efficient causes for their projects. Unfortunately no science theories, including evolutionism, talk about such efficient causes. The following law is very fundamental and may be quite obvious, once you know it and understand it:

Law1: Effect is ever existent [Virupakashnanda] (SK.9).

In observation 2 we find that the pot was already there inside the clay. The potter only extracted it out from the clay. All that happened is only a transformation of the clay to a different shape. Thus the effect was hidden in the material cause. This also shows that the cause and effect are similar in essence. Things that are nonexistent can never become existent. Thus the effect is eternally existent inside the material cause.

This is the law of conservation that we know from physics. Bible also has a similar statement - "There is nothing new under the sun". To create a specific product you not only need specific material, you also must find a specific person trained, skilled, and efficient in that technology. Not anybody and any material can make the product happen. All efficient causes must have these properties - skilled, conscious, intelligent, etc.

\section{Root Causes}

We have two types of causes, material and efficient. We trace each one to find the corresponding root causes. Since these causes are two distinct types, we will find two distinct types of root causes also.

Matter: Take any object in nature and ask the question what this material is composed of. You will find a few new materials. You can then repeat the same question again for all of these new component materials and this way you will find many more new materials. But after a finite number of iterations you will come to a same root material for all new materials. The iterations will be finite because the universe has only a finite number of objects. This final root material must be invisible, otherwise you will have to ask the same question again. This root material must be causeless or unmanifested. This invisible 
particle must have caused all the materials, because all effects must remain hidden in the material causes, by law1. This invisible root material must be the tiniest particle, because it produced the tiniest visible object.

You will not be able to see the root material using your ordinary eyes. You must acquire highly sensitive vision, called the third eye, as we have demonstrated in the yogic power section, to see such normally invisible objects and their characteristics. This root material is called the primordial nature, nature, matter, or prakriti in Sanskrit. Bible calls it dust. This dust is not the dust on our earth, but it is the cosmic dust, that spans the entire universe. All objects of the universe are created from this root material. Thus in a very rational way, by repeated questions, we can find the invisible, eternally existent, and unmanifested root material.

Soul: Along the same line, if you ask repeatedly - what causes this efficient cause - you will ultimately arrive at the root efficient cause, after a finite number of repetitions. This root efficient cause is called the atman, soul, or spirit. It has the consciousness property, because it is efficient. This root efficient cause must also be a tiniest, invisible, and eternally existent, uncaused or unmanifested, particle for the same reasons we have used for the root material cause. Thus we have demonstrated the existence of soul in a very rational way, by asking a simple question repeatedly. Since everything is originated by this soul, every object in the universe has a soul, and that soul has created that object using the root material. Bible says - "God is spirit", and spirit is same as soul. Thus the idea of root efficient cause, which is the individual god, or individual creator, is deeply embedded in the Bible also. We will later give three other independent proofs for the existence of soul.

\section{Eternally Existent}

Law2: The unmanifested cause exists [Virupakashnanda] (SK.15-16)
This law explains why both root material cause and root efficient cause exist for eternity. One of the major reasons we could come to the root cause is because our questioning had stopped due to the finite nature of the universe. As a result the root causes had to be invisible, causeless or unmanifested, i.e. objects without any further cause behind them. If there were no unmanifested causes then we would have found infinite number of objects in the universe, which is not meaningful. Just like oxygen and nitrogen molecules span the entire atmosphere of the earth, and they are finite in numbers, similarly the root material and the root efficient cause particles also cover the entire universe and are finite.

These two types of particles, matter and soul, must be eternally existent - because nonexistent cannot become existent. This also means all effects must be eternally existent inside the root material cause by Law1. Thus the universe must have emerged from this cosmic dust as Bible has mentioned. When the universe dies, it will definitely die because all manifested objects die, then it will merge into this root material. These ever existent root causes will be visible to any high level yogi at any time, including the modern times.

We see that all objects are homogeneous in nature, that is, they all have the property of knowledge, ignorance, and energy. All objects go through a birth maturity and death process. We see in yogic power section that all objects have consciousness, intelligence, mind etc. In reality every object has a subtle body, which contains mind, intelligence, and the identity, and few other things, as shown in Figure-3. This homogeneity or unified design means the existence of same unmanifested root causes, having these properties.

Similarly, all objects have different characteristics which must come from the efficiency of the root efficient cause and characteristics of root material cause. All objects are made from root material which has three properties Sattya (truth, light, 
knowledge), Tamas which is the opposite of sattya or ignorance, and Rajas which means mobility, energy, controller, etc. These properties combine at different proportions and continuously vary according to the desire of the soul. Thus object characteristics are not finite, not discrete, and can vary continuously, which creates distinct destiny for every individual in every incarnation.

It is this combination of the three properties of the unmanifested root material cause that changes the human body and gives the capability of flotation, transparency from camera, ability to pass through walls, protection from diseases, healing powers, etc. These are the combinations that tune our body to remain better connected to our soul. These three properties are like Red, Green, Blue (RGB) colors of our television screens, which can give the infinite variety of colors by controlling their proportionality. Such abilities can be acquired by birth also, as we see in the yogic power section, and will explain many observations in evolutionism.

\section{Theory Of Creation}

Law3: Nature exhibits to the soul, and the soul wants to enjoy, learn, and emancipate. Therefore the matter and the soul join together like a union between the lame and the blind. From this conjunction proceeds the creation [Virupakashnanda] (SK.21).

Thus, I got excited seeing the beauty of nature, and my soul created my physical body to enjoy the nature. But because of the three properties I got delusional and experienced suffering. Nobel Laureate Poet Rabindranath [Tagore] said - "I am a lost traveler visiting your world". Then over many life times, through the yogic meditation we learn to control the three properties to acquire a physical body that can help us to emancipate. But we cannot escape reincarnation [Prabhupada] (Gita 2:27), because we are guided by the destiny [Das, 2013-2]. We can compare and say according to the Bible - a spirit joins the dust to create an object of the universe.
Existence Of Soul: Theories described in Vedas are not fictitious. These theories can be verified by observing the nature, as mentioned in the definition of truth. Although the Vedas were discovered by using yogic meditation, the results can be observed in nature in every decade in every century, by any careful observer, like Galileo. Ian Stevenson [Stevenson] was one such observer, and the following descriptions can be found from some of his research papers. Some say - Stevenson will be considered as the Galileo of the modern century. Both Galileo and Stevenson were high level yogis. The two examples will prove the existence of soul among other things.

Observation3: A baby boy was born in a hospital with birthmarks of a bullet wound on his chest and back. When the boy learned to speak, he casually but spontaneously, talked about his past life, which can be summarized as the following. His name was $\mathrm{N}$ in previous life. He died in hospital $\mathrm{H}$ of town $\mathrm{T}$ on date $\mathrm{D}$, due to a gunshot wound on his chest. Over time, the research scholars, news reporters, parents visited the hospital $\mathrm{H}$ and verified everything that the boy had said from the autopsy records of the man named $\mathrm{N}$, who indeed died on the date D. Such a kid, who remembers his/her past life, is known as Jatiswar in Sanskrit.

On another such jatiswar case [Pasricha], the boy had complications, and the doctors had to perform surgery on the boy to save him. The doctors found the complete straight line bullet path inside the body of the baby, exactly matching the autopsy record of the dead man of the boy's previous life. For more observations and details see [Das, 2014-2], and the references mentioned there.

Consequences Of Observation3: From the above Observation3 we can draw the following conclusions. (a) The babies are not naturally grown inside the mother's womb. The soul of the baby manufactures the human body according to its own destiny. 
That is why every baby is different, both physically and mentally. (b) Since during the growth period, there was no brain for the baby, all intelligences and effects came from the soul of the baby, which is the origin of the efficient cause. (c) Soul controls all our activities, including the genetic code, according to the destiny of our life, right from the conception. (d) Nothing can happen to, or can be performed by any object in the universe, without the explicit command from the soul of that object [Virupakashnanda] (SK.31). (e) Thus physical changes found in fossils cannot happen due to the evolutionism theory, and these Jatiswars prove the existence of soul, reincarnation, yogic powers, gods, and also the creationism. (f) All objects are different, including two animals, and two humans.

\section{There Is No God}

This research is not about atheism or theism, it is about giving proof by direct observation of nature, just like Galileo did, and can be found in Vedas as pointed out. Veda is not about religions, Hinduism is, and Hinduism does not follow Vedas, just like Christianity does not also follow Bible.

Brahma, Vishnu, and Shiva are considered as Gods by Hinduism. Some Upanishads say that they are the creators of the universe, but such Upanishads are not known to be written by seer yogis. And Vedas do not say that they are the creators of the universe. They are the highest level seer yogis. They also reincarnate like humans, and they are also guided by the global destiny of the universe.

From the discussions on Observation3, and the analysis of root causes, we find that every object is created by its own individual soul. That is, you are created by your own soul and I am created by my own soul. This then means that there is no God who has created the entire universe. If we accept that there is such a God then it will create two contradictions: (1) who created such a God and (2) such a God will be under the control of destiny, since all events in nature are precisely predictable by any high level yogi.

\section{Yogic Powers}

Nothing from any religious books, like Vedas or Bible, can be understood without a thorough knowledge of yoga, yogic meditation, and yogic powers. Yoga is the foundation of Vedas. Vedas are considered to describe eternal knowledge or truths, recorded permanently in the memory of the universe, and were discovered only by yogic methods. You can see this truth by your own eyes if you acquire such yogic powers via yogic meditation. There are many books [Govinda, Rama, Yogananda, Brunton] in the yogic literature written by yogis about their own Master yogis (Gurus). Some of these magical powers have been reviewed, and summarized their contents, in the yogic power chapter of the free e-book on soul theory [Das, 2014-2].

One such yogi was Swami Rama, who visited a research institute in USA during the early part of 1970s. He was the first yogi from India, to allow himself for scientific testing on his yogic powers of human physical bodies. These experimental results are documented in the book [Green] and the relevant parts of it are available free on the internet. The results appeared on all major US TV channels, magazines, and science books during that period.

The yogic powers that modern masters have demonstrated can be found in Vedas (Ramayan, Mahabharat, Puran), in Bible, and also in the books of Judaism. This fact also proves that there was a time when Vedas were known all over the world. As a result high level yogis are still here in all continents, in our present days. In the yoga world Shiva is considered as the original or first guru and inventor of all yoga methods. Nobody can surpass his powers as he demonstrated and are described in Purans. Living objects like UFO-ETs have also demonstrated the same yogic powers at much higher levels and in numbers than our present day earth yogis. If you think 
government or money power will tell you the truth about UFO-ETs then you will never learn about them. You must become a seeker, and only then you will find that all truths are there on the internet. Thus Vedas are not just for earth, it is for the entire universe. The fact that UFO-ETs know yoga proves that nobody invented Vedas, and it is written in the memory of the universe.

Bible says - "Be still". This is nothing but making your mind and physical body motionless, unperturbed. This is the first principle for yogic meditation. Bible also says - "If you have the ears then you will hear." That is, using meditation prepare your sense organs, like ear, nose, eyes, etc. Better you prepare them, better will be your connections to your soul and to all the souls of the universe. You will be able to hear the sounds or songs of the synchronized nature of the destiny. Such Bible statements prove that yoga is not new to the western world.

Experiments on Yogis: Swami Rama has demonstrated [Green] that he can raise the temperature on two edges of the same palm of his one hand. The colors at two edges were different also. The temperatures were measured using thermistors and other recording devices. In another experiment he reduced his heart beat from 74 to 52 beats per minute. He also demonstrated that the $\mathrm{T}$ waves were taller than the $\mathrm{R}$ waves, indicating differential control of different sections of the heart. Using EKG machine he also demonstrated that his heart fluttered at a very high rate averaging 306 beats per minute for 16.2 seconds. This will show no pulse rate on chest. He could create a tumor at any place in his body and eventually make it disappear also. He was photographed with a body chakra, situated on spinal cord, glowing on his chest.

It is also well known that Masters are transparent to camera photography, that is, they cannot be seen in photographs. Thus human body can be completely changed by mental power alone. Swami Rama said a very deep level truth - "Our entire physical body is inside our mind, but no part of mind is inside the body". It is then quite natural that animals also will be able to change their forms as detected in their fossils, using their own yogic powers. Thus animal body evolution is a result of soul power and guided by destiny. Animals also do not have freewill.

Placebo surgery: A police officer threw his ax to a man, suspected of murdering [Yogananda] and running away from the crime scene, which partially chopped his hand. But the man was still running and severely bleeding. The police eventually stopped him, realized that he was a yogi, and expressed his deep sorrow and forgiveness. The yogi adjusted his hand back to its correct position and the bleeding stopped immediately. The yogi then said to the police officer, come after three days, under that tree, to examine the wound. With unbelievable surprise the officer found that the wound was completely gone with no marks of cuts or scars.

An UFO-ET broke his leg when the UFO crashed in a Brazil site. The military called a local doctor to fix it. As soon as the doctor put the broken bones together, he immediately started healing, and next morning he was completely cured. This incident was described by the doctor, who was told to remain silent, almost twenty years later to a Hollywood film director who went there for research for his film on UFO. There is a YouTube video on the subject. Thus placebo surgery is a simple fact for any high level yogi.

Defying gravity: Trailanga swami demonstrated floating over water, passing through walls. UFO- ETs also pass through the walls when they abduct humans. They can make their human abductees to float with them and pass through walls to their UFO. So, there are some yogic miracles on the normal human body that can make us float, pass through the walls, make our body transparent to camera, change their body forms, etc. Why not then the same things can happen for some animals and creatures on earth as demonstrated by their fossils? 
Therefore, these are not evolutionism, but clear cases of creationism, created by their individual souls and according to the destiny. This also shows that genetic code is not fundamental for physiology, the code is simply an effect. Such examples prove that modern science does not understand gravity.

Yogic powers by birth: Nature has demonstrated that people can be born with yogic powers, but with limited capabilities and for limited areas only. Magnus Carlsen (1990-) is an world champion chess player. He could see [CBS] the chess boards without looking at them. He defeated ten players, playing simultaneously, sitting behind his back, and without looking at their boards. Carlsen had this divine vision (third eye) only for chess board game, and not for anything else.

Nandana (2004-) a 9-year old autistic girl could read [Saseendran] her mother's mind continuously and completely. She was tested by giving her mother a large number to read from a paper, and the daughter immediately typed it correctly on her computer. Similarly, her mother was given two lines of English sentences to read, and the daughter reproduced it on her computer. We can see that such powers are very limited. But anybody can acquire them at much higher level using yogic meditation, depending on the quality of meditation. If humans can, then animals can be born with yogic powers also explaining the root cause of evolutionism.

$\boldsymbol{U F O}$-ETs and ET-human hybrids are all very high level yogis by birth and probably they do not need any yogic meditation to acquire such powers. Such observations are not found in Vedas and even in ancient Vedic periods. ETs can transfer their yogic powers very easily to human abductees. The body implants recovered from UFO-ET human abductees have also yogic powers. Such materials can grow human tissues in them; they can even get joined together automatically when broken; they are very hard to break though; diamond cutters cannot cut them. They stop functioning when taken out of the bodies of the abductees [Das, 2017 1-2].

External form changes: All the changes that the evolution theorists have noticed in the fossils can be explained by yogic powers of souls. Such observation of yogic powers prove that more sophisticated and exotic observations of completely changing or transforming human body to a different animal, like a tiger, as described in the Mahabharat story, is absolutely meaningful and feasible. Creating a human being, without human sexual relations, and out of nothing with very specialized physical and mental characteristics, are described in Bible, Vedas, and also in the books of Judaism. Modern yogic literature has described a wide variety of human experiences that cannot be documented in such a short paper. A little thinking will show that every activity is a yogic activity. The fact that I am moving my hand is the power of my soul. Without a soul I will be dead even with a perfect body; and has been demonstrated by Master yogis [Govinda, Rama].

Transferring soul: A yogi with a very old physical body came to know that a dead body in good condition of a young man will come floating on a river at some location. The yogi went there, picked up the dead body from the river and then cast off his own old body, his soul entered the young dead body, and he continued to live in that body as a young man [Rama]. He had his all memory, his walking style, and voice of the old man. This was possible because he was a high level yogi. This example shows that a soul knows how to wake up and control a different dead body. It will be impossible to imagine such a capability for our computers. In a broken computer, whose program you do not know, and if you replace the memory chip with new chip, with your own program, then you can be $100 \%$ sure that the computer will not work. We do not have such a technology.

In another similar case, two young boys died around same time and in close distance. 
One body was very heavily damaged. The soul of the damaged body entered the other body and continued to live in that body with the memory and history of the damaged body. This boy then told people what happened to him, and gave convincing proofs to his local people [Stevenson]. This boy was not a yogi, therefore this incident happened automatically by destiny only. Every event is a destiny event, but in the first example we can see many related events happened before switching the body.

These examples prove that the souls exist, we all have souls, and the soul is the controller. There are many proofs of existence of souls in the all three areas of: yogic power, destiny, and reincarnation [Das 2014-2]. None of these capabilities can be proven by evolutionism. On the other hand the evolutionism is clearly explained by the yogic power of souls and the destiny law.

Predictions before birth: It is possible to predict when and where you will be born and with what features. It will be equally feasible to do the same predictions for any object in the universe, depending on the quality of the high level yogi. Thus the evolution of every object can be predicted too before it happens.

A Himalayan yogi came down to a city to meet an old aged couple and told them that eighteen months later they will give birth to a baby boy, who will have a hole in his right ear. And the yogi will take the boy some years later as his student. This boy eventually became Swami Rama.

In India there are about one million palm leaf booklets written at least ten thousand years back that describe the life events of that many people who are living now in our world. They have proven to be very accurate. They were written independently by two very high level seer yogis. Many people from all over the world go to such centers to learn about their predictions. Some prediction results are described in [Das 2014-2]. The fact is that the video of the entire universe is written in the memory of the universe. Anyone with high level yogic power of third eye will be able to see this video and predict the details exactly. The examples of evolution can be visible in the same way, and will prove that it is the power of soul that controls the evolution.

\section{Yogic Power In Animals}

Oscar, the cat, used to live in a nursing home. Doctors found that he could recognize the death time of a patient, and go on to the bed of that patient, two hours before the death, and sit quietly there, to give the parting comfort. The cat was successful perfectly for all times. Doctors began to rely on his ability and used the event to call the relatives to meet their patient for the last time. The cat's performance was documented in a medical journal [David]. You can explain many ways the events but that does not eliminate destiny and yogic powers of the cat. Ability to explain an event is not the same thing as ability to correctly predict the event. Destiny is a consequence of cause and effect, sow and reap, so there will be always reasons for everything. Since destiny is created by simultaneous actionreaction of all objects, there are millions of reasons for every event. As mentioned before, the last question can never be answered however, without a soul as the root cause.

Monarch butterfly is another case of yogic power of insects, which is acquired by birth, in such butterflies. They fly from the east coast of Canada to the west coast of Mexico, seasonally, for more than 3000 miles. But they cannot make it in one life; they die, reincarnate, and continue on their path again. Scientists have tried to divert them from their path by catching them and releasing them at some other place, but they go back to their original track [Bittel]. It shows that the destiny trajectory cannot be broken by death. Memory is not in the brain, but it is in the universe, and a soul can know it naturally. We are all guided by the destiny, and nobody can change that. Thus evolution 
is not controlled by that animal or human, nor by nature, but by its soul and its destiny.

Yogic power is the highest level power, and is much stronger than the nuclear power. You can imagine the power of the sun. It has a soul too, and that soul has created that sun. The sun is protecting our entire solar system, helping them to survive using its light and energy. Anything that you can imagine, a soul can produce or create that, and has already been created by some soul, somewhere in the universe.

\section{Yogic Power In Materials}

Changing Water Crystals: A Japanese scientists, Masaru Emoto, demonstrated [Nemoto] that the physical shape of water crystals can be changed by showing our emotions to water. In his one of the experiments, he took a bottle of water and poured in two glasses, and placed two labels expressing your positive and negative emotions. Then he had frozen the water to form crystals and took photographs of them, and shown that the one with positive emotion gives better designed crystals than the other one. This experiment shows that everything around us has consciousness or soul and can be influenced by our own intentions, and with appropriate technology we can detect their effects.

Controlling Electronics: Princeton university carried out experiments [Jahn] on human interaction with electronic circuits. A random number generator was created using electronic devices and was hooked up to a computer system display. A human operator meditated in front of the device, but was not electronically connected to the machines. It was found that the mean value of the random generator could be controlled and increased over time, gradually, by performing meditation to increase it. In the same way, the meditator was able to influence the device to lower the mean value to below the normal mean value. The experiment shows that the material objects also have souls and they can interact with human souls. Thus every object in the entire universe has a soul.
Body Implants: Body implants extracted from the human abductees by UFO-ETs have significant yogic powers. Such implants can grow human tissues from them. If you break the implant, and bring them together, they can rejoin automatically. Such implants do not cause infections in the human body, and the humans do not reject them either.

\section{Who Wrote Vedas}

We have described the nature of yogic powers in the previous section. We have seen that using yogic power you can achieve anything and everything. Vedas are observed by yogis with third eye vision, such yogis are called seer yogis or Drashta in Sanskrit. The nature of things that a seer yogi can see is described in Mahabharat and Gita, and is presented in this article by many examples.

Veda is stored as a video in the memory of the universe. This video describes everything that has happened in the past, is happening now, and will happen in the future. This memory defines the destiny of the universe. Thus nobody has written Vedas. Many seer yogis have seen this video and then told others, and they eventually wrote it down. Only parts of Vedas that are narrated by a seer yogi are considered as Vedas. All other parts of Vedas should not be considered as eternal and universal. It is well known that Ramayan, Mahabharat, Gita, and Samkhya are written by seer yogis.

If you can acquire high quality third eye vision then you will also be able to see the Vedas even today, because memory of the universe is protected by the law of conservation. Not anybody, like you and I, can write Vedas. We have described examples of yogic powers for UFO-ETs. Such examples prove that the written parts of Vedas are valid for the entire universe.

\section{Conclusions}

The foundation of the Vedic science is yogic power. Without a thorough understanding of yogic power, the concepts behind all religious books cannot be 
comprehended. All aspects of Vedic science can be observed in nature. A definition of truth is given, which includes that nature always demonstrates its truths. This article described many examples of such demonstrations. A distinct difference with the modern science is that the Vedic science recognizes two types of causes - efficient cause and material cause. Unfortunately the modern science has never considered the efficient cause, even though modern engineering always uses the efficient cause in all its activities. Vedic science also recognized the existence of root causes for both types of cause, which is missing in the modern science. Vedas call the root efficient cause as atman or soul. Thus every object in the universe has a soul; and that individual soul is the creator of that individual object.

\section{References}

Bernanke, B. S., \& Blinder, A. S., (1992), The federal funds rate and the channels of monetary transmission, Am. Econ. Rev., Vol 82, No. 4, pp. 901-921

Billiards, Billiards and Pool, Game photo, 2012 http://downloadfullcracks.blogspot.com/2012/06/billiar ds-and- pool-play-free-online.html

B i t t e $1 \mathrm{~J}$; Monarch Butterflies Migrate 3,000 Miles-Here's How, P u b 1 i s h e d October 17, 2017 https://news.nationalgeographic.com/2 017/10/monarch-butterfly-migration/

Brunton P. A search in secret India, A Book, First published in England in 1934, Rider \& Company, London, First American paper back, Samuel Weiser Inc., York Beach, Maine 03910, 1970. http://sageevans.businesscatalyst.com/ downloads/Paul-Brunton-A-Search-inSecret-India.pdf, free on the internet.

CBS News, Mozart of Chess Magnus Carlsen - Wins 10 people at the same time in blind, 60 minutes, 2014, https://www.youtube.com/watch?v=cT eDkyQUbyY

Das S, 2011-1, Finite Time Engineering, Proceedings of the World Congress on
Engineering and Computer Science 2011 Vol II, WCECS 2011, October 19-21, San Francisco, USA. Available free from: http://www.iaeng.org/publication/WC ECS2011/WCECS2011_pp10011006.pdf

Das S, 2011-2, "Federal Reserve's Plan to Transfer Wealth", 2011 conference proceedings, Northeast business and economic association, pp. 564-570, Philadelphia, Pennsylvania, USA, Nov 3-5.

Das S, 2012-1, Conservation laws of nature, Journal of Applied Global Research, Vol. 5, Issue 12

Das S, 2012-2, "Rethinking embedded system design", International Journal of Engineering (IJE), volume (6) : issue (2) : pp. 70-85.

Das S, 2012-3, Moneyless economy, The business review, Cambridge, Vol. 20, No. 1, Summer, 2012, pp. 17-25. Awarded Best Paper.

Das S, 2013-1, Assumptions in Quantum Mechanics, International Journal of Theoretical and Mathematical Physics 2013, 3(2): 53-68 DOI: 10.5923/j.ijtmp.20130302.02, available free at https://www.academia.edu/8353369/A ssumptions_in_Quantum_Mechanics

Das S, 2013-2, A scientific theory of destiny, Global Journal of Science Frontier Research, Mathematics and Decision Sciences, 60 pages, Volume 13 Issue 8 Version 1.0 Year 2013.

Das S, 2014-1, Michelson-Morley experiment proves light speed is not constant, Physics Essays 27, 1,2014

Das S, 2014-2, Soul Theory, eBook, https://theoryofsouls.wordpress.com/, 2014, free on the internet.

Das S, 2017-1, Body Implants, Quora Answer, July 2017, https://www.quora.com/What-is-thevery-best-piece- of-evidence-of-alienUFOs/answer/Subhendu-Das14 ? share $=\mathrm{f} 42 \mathrm{~b} 18 \mathrm{~d} 4 \&$ srid $=\mathrm{gkgM}$ 
Das S, 2017-2, RAECHEL'S EYES, Quora Answer, August, 2017, https://www.quora.com/Is-it-possibleto-heal- the-body-through-thought-ormeditation/answer/Subhendu-Das14 ? share $=7128 \mathrm{~d} 717 \&$ srid $=\mathrm{gkgM}$

David D. 2007, Oscar the cat, https://en.wikipedia.org/wiki/Oscar_(th erapy cat)

Ferraro R. Einstein's Space-time, Springer, 2007

Francisco J A. Author committee chair, University of California, Irvine, National Academy of Sciences and Institute of Medicine (2008). Science, Evolution, and Creationism. Washington, D.C.: The National Academies Press. 88 pages, $8 \times 10$, (2008), free in pdf from http://www.nap.edu/catalog/11876.htm 1

Govinda L. The way of the white clouds, A Book, Boston, Shambhala, 1988, Pages 207.

Green E, Green A. Beyond Biofeedback, A Book, A Merloyd Lawrence Book, 368 pages, USA, 1977.

Jahn R G, Dunne B J, Nelson R D, Dobyns $\mathrm{Y} H$, and $\mathrm{G}$. J. Bradish $\mathrm{G} \mathrm{H}$, Correlations of Random Binary Sequences with Pre-Stated Operator Intention: A Review of a 12-Year Program, Princeton Engineering Anomalies Research (PEAR), School of Engineering and Applied Science, Princeton University, Journal of Scientific Exploration, Vol. 11, No. 3, pp. 345-367, 1997.

Michael G. The man who could fly: St. Joseph of Copertino (2015), History's Most Outstanding Case of Levitation, Witnessed by Multitudes: Expert Discusses,

https://www.theepochtimes.com/histor

ys-mostoutstanding-case-of-

levitation-witnessed-by-multitudes-

expert-discusses_1413136.html

Nemoto Y. Message from water and science, Nineth annual conference on the physics, chemistry, and biology of water, October 9-12, 2014, Bulgaria.

Pasricha S K, Keil J, Tucker J B, Stevenson I. Some Bodily Malformations Attributed to Previous Lives, Journal of Scientific Exploration, Vol. 19, No. 3, 2005, pp. 359-383.

Phillips A C. Introduction to Quantum Mechanics, Department of Physics and Astronomy, University of Manchester, 2003, John Wiley \& Sons Ltd, England.

Prabhupada A C B S. Bhagavad-Gita, as it is, Publisher: Bhaktivedanta book trust, USA, 1994, free on the internet.

Quigley C. Tragedy and hope, A history of the world in our time, 1367 Pages, Macmillan company, NY, 1966, http://www.carrollquigley.net/pdf/Trag edy_and_Hope.pdf, free on the internet.

Rama S. Living with the Himalayan Masters, A Book, Himalayan institute press, 2007, 153 pages.

Rankin L. Is there scientific proof we can heal ourselves? YouTube Video, 18:50 minutes, Lissa Rankin, MD, TEDxAmericanRiviera, Published on Dec 18, 2012, https://www.youtube.com/watch?v=L WQfe fNbs

Ray S. Hirok Rajar Deshe, lit. "in the land of the Diamond King", Bengali film from Kolkata, India, 1980, https://en.wikipedia.org/wiki/Hirak_Ra jar_Deshe

Roy P C. The Mahabharata of KrishnaDwaipayana Vyasa, Bhishma parva, Vols. 1-10, ND, free on the internet.

Saseendran S. Miracle Girl: Nandana has access to mother's memory, 25 March 2013, Khaleej Times, http://www.khaleejtimes.com/ktarticle-display1.asp?xfile=data/todayevent $/ 2013 / \mathrm{mar}$ ch/todayevent_march36.xml\&section= todayevent 
Serway R A, Jewett J W. Physics for Scientists and Engineers with Modern Physics, A Book, Ninth Edition,

Brooks/Cole, Boston, MA 02210, USA, 2014, Available free on the internet in PDF, p. 1198.

Stevenson I. Twenty cases suggestive of reincarnation, A Book, Univ. press of Virginia, Charlottesville, Second Edition, 1974.

Tagore $\mathrm{R}$ N. Rabindra rachanabali, in Bengali language, 2010, India, http://www.rabindrarachanabali.nltr.org/node/1, Ami path bhola ek pathik.

Trench W F, Introduction to real analysis, Edition 2.04, 2013, Open Textbook Initiative.

Twain M. The Complete Works of Mark Twain (Authorized Edition), 1922, also in Google books, https://books.google.com/books?isbn= 8026878140
Yogananda P. Autobiography of a yogi, A Book, Self-realization fellowship publisher, Los Angeles, CA, USA, 1979.

YouTube-2014, Powers of the mind, You are creators, https://www.youtube.com/watch?v=N njJCs4YUCA

YouTube-2012, Real Magic? - Levitating Monk - Can You Believe Your Eyes The Supernaturalist on Discovery, https://www.youtube.com/watch?v=B ShBXdlStWU, 2:50 minutes. This is part of a longer video.

Virupakashnanda S. Samkhya Karika. A Book, 72 pages, Publisher: Sri Ramakrishna Math, Mylapore, Madras, India, 1995, free pdf on the internet.

Vivekananda S. Practical Vedanta, 12. A study of Sankhya philosophy, Lecture delivered in London, 1896. 